\title{
Dynamic Behavior of Axially Functionally Graded Pipes Conveying Fluid
}

\author{
Chen $\mathrm{An}^{1}$ and Jian $\mathrm{Su}^{2}$ \\ ${ }^{1}$ Institute for Ocean Engineering, China University of Petroleum-Beijing, Beijing 102249, China \\ ${ }^{2}$ Nuclear Engineering Program, COPPE, Universidade Federal do Rio de Janeiro, CP 68509, 21941-972 Rio de Janeiro, RJ, Brazil \\ Correspondence should be addressed to Jian Su; sujian@lasme.coppe.ufrj.br
}

Received 1 March 2016; Accepted 13 November 2016; Published 1 January 2017

Academic Editor: Michael Mazilu

Copyright (C) 2017 C. An and J. Su. This is an open access article distributed under the Creative Commons Attribution License, which permits unrestricted use, distribution, and reproduction in any medium, provided the original work is properly cited.

\begin{abstract}
Dynamic behavior of axially functionally graded (FG) pipes conveying fluid was investigated numerically by using the generalized integral transform technique (GITT). The transverse vibration equation was integral transformed into a coupled system of secondorder differential equations in the temporal variable. The Mathematica's built-in function, NDSolve, was employed to numerically solve the resulting transformed ODE system. Excellent convergence of the proposed eigenfunction expansions was demonstrated for calculating the transverse displacement at various points of axially FG pipes conveying fluid. The proposed approach was verified by comparing the obtained results with the available solutions reported in the literature. Moreover, parametric studies were performed to analyze the effects of Young's modulus variation, material distribution, and flow velocity on the dynamic behavior of axially FG pipes conveying fluid.
\end{abstract}

\section{Introduction}

Pipelines conveying fluid exist widely in many application fields, particularly in nuclear power plants, chemical plants, aeronautic, oil transportation, water supply, heat exchanger devices, human circulation, and so forth. The high velocity internal flow may cause severe flow-induced vibration of piping systems, which may further result in leakages, fatigue failures, high noise, fire, and explosions of the pipes [1]. Extensive investigations have been carried out in the past decades to understand the dynamical behavior of pipes conveying fluid, as described by Païdoussis and Li [2] and Païdoussis [3, 4].

Similar to other structural dynamic problems, the earliest concern of fluid-conveying pipes was the free vibration response [5]. Research reveals that the boundary conditions can affect significantly the natural frequencies of the dynamic systems $[6,7]$. Some numerical methods such as homotopy perturbation method [8] and precise integration method [9] were developed to analyze the effect of fluid flow velocity on the natural frequencies. Although there are many studies considering the flow velocity as constant, the flow velocity varies with time for the actual industrial problems. The unsteady flow is usually modeled by the superposition of the steady flow and a time-dependent harmonic component, which may induce the dynamic instability due to parametric resonances [10]. For instance, Jin and Song [11] investigated the effect of some physical parameters of the system, such as damping, mean flow velocity, mass ratio, tension, and gravity, on the three regions of parametric resonances of pipes with supported ends conveying pulsating fluid. Panda and Kar [12] analyzed the nonlinear planar vibration of a hinged-hinged pipe conveying fluid with harmonic flow velocity pulsation in the presence of internal resonance. With the development of material technology and application, new materials exhibiting viscoelastic behaviors such as polymer matrix composites are now widely used for pipes. Zhao et al. [13] investigated the dynamic behavior and stability of Maxwell viscoelastic pipes conveying fluid with simply supported ends. Zhang et al. [14] presented a viscoelastic finite element approach to the vibration analysis of viscoelastic Timoshenko pipes conveying fluid. Wang et al. [15] studied the vibration and stability of viscoelastic curved pipes conveying fluid using normalized power series method. Yang et al. [16] investigated the dynamic stability for the transverse vibrations of pipes 
conveying fluid using the method of multiple scales. To avoid the failure caused by resonance due to the excitation of external forces, many researchers considered the forced vibrations of pipes conveying fluid. Gulyayev and Tolbatov [17] carried out the numerical modelling of self-excited vibrations of tubes containing inner flows of nonhomogeneous boiling fluid. Seo et al. [18] presented the finite element method to predict the forced vibration response of a pipe conveying harmonically pulsating fluid. Liang and Wen [19] studied the forced responses with both an internal resonance and an external periodic excitation of the constant-fluid-conveying pipe by the multidimensional Lindstedt-Poincaré method. In practice, most of the load applied on the industrial pipes is random, therefore, the dynamic response of pipes conveying fluid subjected to random excitation was studied by Zhai et al. [20,21]. Since the high-temperature environment should be confronted in some industries such as nuclear reactors, space planes, and chemical plants, the vibration behaviors of pipes conveying fluid under thermal loads have been studied in recent years [22-26].

Due to the advantages of being able to withstand severe high-temperature gradient while maintaining structural integrity, functionally graded materials (FGMs) have attracted great interest in a broad range of applications including biomechanical, automotive, aerospace, mechanical, civil, nuclear, and naval engineering [27, 28], as it is known that FGMs are a novel class of composite materials whose composition and/or function is designed to change continuously within the solid. The composites are usually made from a mixture of metals and ceramics to ensure the elastic and toughness properties gradually vary in space, which can prevent delamination and stress concentration in traditional multilayer, laminated composites. For pipes conveying fluid, Sheng and Wang [24] reported the result of an investigation into the coupled vibration characteristics of fluid-filled functionally graded cylindrical shells, while Hosseini and Fazelzadeh [26] investigated the thermomechanical stability of functionally graded thin-walled cantilever pipes conveying flow and loading by compressive axial force. Both of the above-mentioned investigations assumed that the material properties vary along the thickness direction of pipes; however, dynamic behaviors of axially functionally graded systems (structures with material graduation through the longitudinal directions) should be also concerned, as reported by [29-34]. To the authors' knowledge, the literature dealing with the dynamic behavior of fluid-conveying pipes made of axially FGMs is very limited, which forms the motivation for the current work.

In this study, the dynamic behavior of axially functionally graded (FG) pipes conveying fluid is analytically and numerically investigated on the basis of the generalized integral transform technique (GITT), which has been successfully applied in solving the dynamic response of axially moving beams [35], axially moving orthotropic plates [36], fluidconveying pipes [37] and pipes conveying gas-liquid twophase flow [38], the wind-induced vibration on overhead conductors [39], the vortex-induced vibration of long flexible cylinders [40], and the transverse vibrations of a cantilever beam with an eccentric tip mass in the axial direction [41].

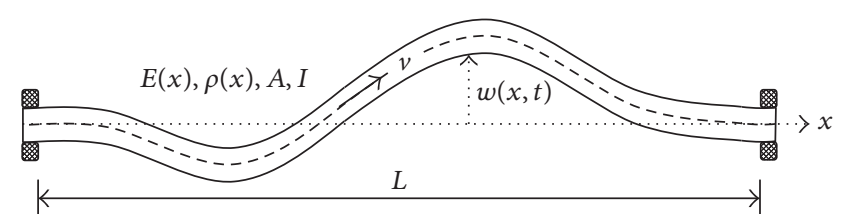

FIGURE 1: Illustration of an axially functionally graded pipe conveying fluid; the transverse displacement of which is described by $w(x, t)$.

From an engineering viewpoint, the novel contribution of this investigation is to generate the reliable reference data on the dynamic behavior of axially FG conveying fluid, while, from a mathematical viewpoint, this work provides a feasible numerical solution of the variable coefficient partial differential equations governing the phenomenon. The rest of paper is organized as follows. In the next section, the mathematical formulation of the transverse vibration problem of axially FG pipes conveying fluid is presented. In Section 3, the hybrid numerical-analytical solution is obtained by carrying out integral transform. Numerical results of proposed method including transverse displacements and their corresponding convergence behavior and verification are presented in Section 4. A parameter study is then performed to investigate the effects of material distributions and mass ratios on natural frequencies and vibration amplitude of pipes conveying fluid, respectively. Besides, the variation of the dimensionless frequencies with Young's modulus ratio, power exponent, and flow velocity are also presented. Finally, the paper ends in Section 5 with conclusions and perspectives.

\section{Mathematical Formulation}

We consider a fluid-conveying pipe made of axially functionally graded (FG) material based on Euler-Bernoulli beam theory, as illustrated in Figure 1. If gravity, internal damping, external imposed tension, and pressurization effects are either absent or neglected, the equation of motion of the FG pipe can be derived following the Newtonian derivation by means of decomposing an infinitesimal pipe-fluid element into the pipe element and the fluid element, according to the procedure given by Païdoussis [3]:

$$
\begin{aligned}
& \frac{\partial^{2}}{\partial x^{2}}\left[E(x) I \frac{\partial^{2} w}{\partial x^{2}}\right]+m_{f} v^{2} \frac{\partial^{2} w}{\partial x^{2}}+2 m_{f} v \frac{\partial^{2} w}{\partial x \partial t} \\
& \quad+\left[m_{f}+\rho(x) A\right] \frac{\partial^{2} w}{\partial t^{2}}=0,
\end{aligned}
$$

subjected to the clamped-clamped boundary conditions

$$
\begin{gathered}
w(0, t)=0, \\
\frac{\partial w(0, t)}{\partial x}=0, \\
w(L, t)=0, \\
\frac{\partial w(L, t)}{\partial x}=0,
\end{gathered}
$$


where $w(x, t)$ is the transverse displacement, $E(x) I$ is the flexural rigidity of the pipe which depends upon both Young's modulus $E(x)$ and the inertial moment of cross-sectional area $I, m_{f}$ is the mass of fluid per unit length, $v$ is the steady flow velocity, $\rho(x) A$ is the mass of the pipe per unit length which depends upon mass density $\rho(x)$ and crosssectional area $A$, and $L$ is the pipe length. Note that, for the axially FG pipe, $E(x)$ and $\rho(x)$ are functions of the axial coordinate $x$. In addition, we assume that the coefficient of thermal expansion and the thermal conductivity of the FG material are constant along the pipe; therefore, the influence of the thermal environment can be ignored. The following dimensionless variables are introduced:

$$
\begin{aligned}
x^{*} & =\frac{x}{L}, \\
w^{*} & =\frac{w}{L}, \\
t^{*} & =\frac{t}{L^{2}} \sqrt{\frac{E_{0} I}{m_{f}+\rho_{0} A}}, \\
v^{*} & =v L \sqrt{\frac{m_{f}}{E_{0} I}}, \\
\alpha\left(x^{*}\right) & =\frac{E\left(x^{*}\right)}{E_{0}}, \\
\beta & =\sqrt{\frac{m_{f}}{m_{f}+\rho_{0} A}}, \\
\gamma\left(x^{*}\right) & =\frac{m_{f}+\rho\left(x^{*}\right) A}{m_{f}+\rho_{0} A},
\end{aligned}
$$

where $E_{0}$ and $\rho_{0}$ are the corresponding Young's modulus and mass density at the end $x^{*}=0$. Substituting $(2 \mathrm{a})-(2 \mathrm{~g})$ into (1a)-(1e) gives the dimensionless equation (dropping the superposed asterisks for simplicity)

$$
\begin{aligned}
\frac{\partial^{2}}{\partial x^{2}} & {\left[\alpha(x) \frac{\partial^{2} w}{\partial x^{2}}\right]+v^{2} \frac{\partial^{2} w}{\partial x^{2}}+2 \beta v \frac{\partial^{2} w}{\partial x \partial t}+\gamma(x) \frac{\partial^{2} w}{\partial t^{2}} } \\
& =0
\end{aligned}
$$

together with the boundary conditions

$$
\begin{gathered}
w(0, t)=0 \\
\frac{\partial w(0, t)}{\partial x}=0, \\
w(1, t)=0, \\
\frac{\partial w(1, t)}{\partial x}=0 .
\end{gathered}
$$

The initial conditions are defined as follows:

$$
\begin{aligned}
& w(x, 0)=0, \\
& \dot{w}(x, 0)=v_{0} \sin (\pi x) .
\end{aligned}
$$

\section{Integral Transform Solution}

To conduct the integral transform technique, the additional eigenvalue problem should be introduced for the governing equation (3a) with the boundary conditions $(3 b)-(3 e)$. The coordinate " $x$ " is eliminated by using integral transformation, and the eigenvalue problem is employed for the transverse displacement as follows:

$$
\frac{\mathrm{d}^{4} X_{i}(x)}{\mathrm{d} x^{4}}=\mu_{i}^{4} X_{i}(x), \quad 0<x<1,
$$

with the boundary conditions

$$
\begin{aligned}
X_{i}(0) & =0, \\
\frac{\mathrm{d} X_{i}(0)}{\mathrm{d} x} & =0, \\
X_{i}(1) & =0, \\
\frac{\mathrm{d} X_{i}(1)}{\mathrm{d} x} & =0,
\end{aligned}
$$

where $X_{i}(x)$ and $\mu_{i}$ are the eigenfunctions and eigenvalues of problem $(5 \mathrm{a})-(5 \mathrm{e})$, respectively. The orthogonality property should be satisfied by the eigenfunctions

$$
\int_{0}^{1} X_{i}(x) X_{j}(x) \mathrm{d} x=\delta_{i j} N_{i}
$$

with $\delta_{i j}=0$ when $i \neq j$ and $\delta_{i j}=1$ when $i=j$. The norm is defined as

$$
N_{i}=\int_{0}^{1} X_{i}^{2}(x) \mathrm{d} x
$$

Eigenvalue problem (5a)-(5e) can be solved analytically to generate

$$
\begin{aligned}
& X_{i}(x) \\
& = \begin{cases}\frac{\cos \left[\mu_{i}(x-1 / 2)\right]}{\cos \left(\mu_{i} / 2\right)}-\frac{\cosh \left[\mu_{i}(x-1 / 2)\right]}{\cosh \left(\mu_{i} / 2\right)}, & \text { for } i \text { odd, } \\
\frac{\sin \left[\mu_{i}(x-1 / 2)\right]}{\sin \left(\mu_{i} / 2\right)}-\frac{\sinh \left[\mu_{i}(x-1 / 2)\right]}{\sinh \left(\mu_{i} / 2\right)}, & \text { for } i \text { even, }\end{cases}
\end{aligned}
$$

where the eigenvalues are calculated through the transcendental equations:

$$
\tanh \left(\frac{\mu_{i}}{2}\right)= \begin{cases}-\tan \left(\frac{\mu_{i}}{2}\right), & \text { for } i \text { odd } \\ \tan \left(\frac{\mu_{i}}{2}\right), & \text { for } i \text { even }\end{cases}
$$

and the normalization of integral is

$$
N_{i}=1, \quad i=1,2,3, \ldots .
$$

Then, the normalized eigenfunction yields

$$
\widetilde{X}_{i}(x)=\frac{X_{i}(x)}{N_{i}^{1 / 2}} .
$$


For the transverse displacement, the integral transformation and the inversion equations are as follows:

$$
\begin{aligned}
\bar{w}_{i}(t) & =\int_{0}^{1} \widetilde{X}_{i}(x) w(x, t) \mathrm{d} x, \quad \text { transform, } \\
w(x, t) & =\sum_{i=1}^{\infty} \widetilde{X}_{i}(x) \bar{w}_{i}(t), \quad \text { inverse. }
\end{aligned}
$$

Now, the integral transformation procedure is conducted by operation of (3a) with $\int_{0}^{1} \widetilde{X}_{i}(x) \mathrm{d} x$, to obtain the transformed transverse displacement equation system:

$$
\begin{aligned}
\sum_{j=1}^{\infty}\left[A_{i j} \frac{\mathrm{d}^{2} \bar{w}_{j}(t)}{\mathrm{d} t^{2}}+2 \beta v B_{i j} \frac{\mathrm{d} \bar{w}_{j}(t)}{\mathrm{d} t}\right. & \\
\left.+\left(v^{2} C_{i j}+D_{i j}+2 E_{i j}+\mu_{j}^{4} F_{i j}\right) \bar{w}_{j}(t)\right] & =0, \\
i & =1,2,3, \ldots,
\end{aligned}
$$

where the coefficients are given by the integrals below

$$
\begin{aligned}
A_{i j} & =\int_{0}^{1} \gamma(x) \widetilde{X}_{i}(x) \widetilde{X}_{j}(x) \mathrm{d} x, \\
B_{i j} & =\int_{0}^{1} \widetilde{X}_{i}(x) \widetilde{X}_{j}(x)^{\prime} \mathrm{d} x, \\
C_{i j} & =\int_{0}^{1} \widetilde{X}_{i}(x) \widetilde{X}_{j}(x)^{\prime \prime} \mathrm{d} x, \\
D_{i j} & =\int_{0}^{1} \alpha(x)^{\prime \prime} \widetilde{X}_{i}(x) \widetilde{X}_{j}(x)^{\prime \prime} \mathrm{d} x, \\
E_{i j} & =\int_{0}^{1} \alpha(x)^{\prime} \widetilde{X}_{i}(x) \widetilde{X}_{j}(x)^{\prime \prime \prime} \mathrm{d} x, \\
F_{i j} & =\int_{0}^{1} \alpha(x) \widetilde{X}_{i}(x) \widetilde{X}_{j}(x) \mathrm{d} x .
\end{aligned}
$$

In a similar way, the initial conditions can be also transformed to eliminate " $x$ " coordinate:

$$
\begin{aligned}
& \bar{w}_{i}(0)=0 \\
& \frac{\mathrm{d} \bar{w}_{i}(0)}{\mathrm{d} t}=v_{0} \int_{0}^{1} \widetilde{X}_{i}(x) \sin (\pi x) \mathrm{d} x, \\
& \\
& i=1,2,3, \ldots
\end{aligned}
$$

In the computational process, the expansion for the transverse displacement is truncated to finite orders $N W$. Equations (13a)-(13g), (14a), and (14b) in the truncated series are calculated using the NDSolve in Mathematica [43]. Once the values of $\bar{w}_{i}$ are determined, the inversion formulas equation (12b) is subsequently employed to yield explicit expression for the transverse displacement $w(x, t)$.

\section{Results and Discussion}

4.1. Convergence Behavior of the Solution. We now present the convergence behavior of numerical results for the transverse displacement $w(x, t)$ of a functionally graded pipe conveying fluid calculated using the GITT approach. For the case examined, the geometrical parameters adopted by Zhai et al. [20] are taken in (1a)-(1e): $L=1010 \mathrm{~mm}, D=22.85 \mathrm{~mm}$, and $d=19.65 \mathrm{~mm}$, where $D$ and $d$ are the outer and inner diameters of pipe cross section, respectively. In this study, we assume that the material properties of the pipe, such as Young's modulus $E$ and mass density $\rho$, vary continuously as a power law through the pipe axis [34]: $P(x)=\left(P_{L}-P_{R}\right)(1-$ $x / L)^{k}+P_{R}$, where $P_{R}$ and $P_{L}$ are the corresponding material of the right and the left side of the pipe, and $k$ is the nonnegative power-law exponent which dictates the material variation profile through the pipe axis. In the following calculations, aluminum and zirconia are chosen for the corresponding material of the left and the right sides of the pipe, respectively, the material properties of which are [29] $E_{a}=70 \mathrm{GPa}$, $\rho_{a}=2702 \mathrm{~kg} / \mathrm{m}^{3}$ for aluminum, and $E_{z}=200 \mathrm{GPa}, \rho_{z}=$ $5700 \mathrm{~kg} / \mathrm{m}^{3}$ for zirconia. The fluid density conveying in the pipe is $\rho_{f}=1000 \mathrm{~kg} / \mathrm{m}^{3}$. The dimensionless variables can be obtained through $(2 \mathrm{a})-(2 \mathrm{~g})$. The solution of the system, (13a)-(13g), (14a), and (14b), is obtained with $N W \leq 16$ to analyze the convergence behavior.

The dimensionless transverse displacement $w(x, t)$ at different positions, $x=0.1,0.3,0.5,0.7$, and 0.9 , of axially FG pipes conveying fluid is presented in Tables 1 and 2, respectively. The convergence behavior of the integral transform solution is examined for increasing truncation terms $N W=4,8,12$, and 16 at $t=10,20$, and 30, respectively. For the dimensionless transverse displacement with $v=1.0$ and $k=1.0$, it can be observed that convergence is achieved essentially with a reasonably low truncation order $(N \leq 8)$. For a full convergence to three significant digits, more terms (e.g., $N \leq 12$ ) are required. The results at $t=30$ indicate that the excellent convergence behavior of the integral transform solution does not change with time, verifying the good longtime numerical stability of the scheme. For the dimensionless transverse displacement with $v=3.0$ and $k=1.0$, convergence to three significant digits is achieved with truncation order $N \leq 16$, which demonstrates that the increasing of $v$ can make the solution with a relatively slow convergence. For the same cases, the profiles of the transverse displacement at $t=$ 20 are illustrated in Figure 2 with different truncation orders, where it can be clearly seen that the convergence behavior of the integral transform solution for the case of $v=1.0$ is better than the case of $v=3.0$.

4.2. Verification of the Solution. The influence of fluid velocity on the first five dimensionless natural frequencies of axially FG pipes conveying fluid with the power-law exponent $k=$ 1.0 is presented in Table 3. To obtain the natural circular frequencies for the transverse vibration of the system, the coupled ODEs, (13a)-(13g), can be represented in the matrix form as follows:

$$
\mathbf{M} \ddot{\mathbf{w}}(t)+\mathbf{C} \dot{\mathbf{w}}(t)+\mathbf{K w}(t)=\mathbf{F}(t) .
$$


TABLE 1: Convergence behavior of the dimensionless transverse displacement $w(x, t)$ of FG pipes conveying fluid for $v=1.0$ and $k=1.0$.

\begin{tabular}{|c|c|c|c|c|}
\hline$x$ & $N W=4$ & $N W=8$ & $N W=12$ & $N W=16$ \\
\hline \multicolumn{5}{|l|}{$t=10$} \\
\hline 0.1 & 0.0044244 & 0.0037878 & 0.0039159 & 0.0039563 \\
\hline 0.3 & 0.0191635 & 0.0206171 & 0.0206690 & 0.0207072 \\
\hline 0.5 & 0.0207420 & 0.0244299 & 0.0245583 & 0.0246031 \\
\hline 0.7 & 0.0127285 & 0.0124189 & 0.0123877 & 0.0124042 \\
\hline 0.9 & 0.0021788 & 0.0012293 & 0.0012868 & 0.0013476 \\
\hline \multicolumn{5}{|l|}{$t=20$} \\
\hline 0.1 & -0.0060519 & -0.0062440 & -0.0060664 & -0.0060803 \\
\hline 0.3 & -0.0291388 & -0.0296250 & -0.0298559 & -0.0298584 \\
\hline 0.5 & -0.0358924 & -0.0382805 & -0.0382784 & -0.0382978 \\
\hline 0.7 & -0.0235454 & -0.0256259 & -0.0257693 & -0.0257332 \\
\hline 0.9 & -0.0040988 & -0.0044978 & -0.0042350 & -0.0042428 \\
\hline \multicolumn{5}{|l|}{$t=30$} \\
\hline 0.1 & 0.0064297 & 0.0066167 & 0.0064907 & 0.0064724 \\
\hline 0.3 & 0.0325025 & 0.0313819 & 0.0315394 & 0.0315556 \\
\hline 0.5 & 0.0405411 & 0.0390336 & 0.0384158 & 0.0383750 \\
\hline 0.7 & 0.0251618 & 0.0234384 & 0.0238947 & 0.0239246 \\
\hline 0.9 & 0.0040959 & 0.0038549 & 0.0037553 & 0.0037439 \\
\hline
\end{tabular}

TABLE 2: Convergence behavior of the dimensionless transverse displacement $w(x, t)$ of FG pipes conveying fluid for $v=3.0$ and $k=1.0$.

\begin{tabular}{|c|c|c|c|c|}
\hline$x$ & $N W=4$ & $N W=8$ & $N W=12$ & $N W=16$ \\
\hline \multicolumn{5}{|l|}{$t=10$} \\
\hline 0.1 & 0.0030463 & 0.0024006 & 0.0026071 & 0.0026145 \\
\hline 0.3 & 0.0083268 & 0.0100507 & 0.0099890 & 0.0099936 \\
\hline 0.5 & 0.0025960 & 0.0057039 & 0.0059138 & 0.0059497 \\
\hline 0.7 & -0.0013099 & -0.0021990 & -0.0022931 & -0.0023027 \\
\hline 0.9 & -0.0006775 & -0.0011992 & -0.0010060 & -0.0010314 \\
\hline \multicolumn{5}{|l|}{$t=20$} \\
\hline 0.1 & -0.0019432 & -0.0013335 & -0.0015234 & -0.0015166 \\
\hline 0.3 & -0.0071319 & -0.0088004 & -0.0088014 & -0.0088167 \\
\hline 0.5 & -0.0055658 & -0.0118234 & -0.0123907 & -0.0124569 \\
\hline 0.7 & -0.0028723 & -0.0073600 & -0.0070684 & -0.0071240 \\
\hline 0.9 & -0.0005661 & -0.0009220 & -0.0011155 & -0.0011267 \\
\hline \multicolumn{5}{|l|}{$t=30$} \\
\hline 0.1 & 0.0033760 & 0.0043476 & 0.0041930 & 0.0041604 \\
\hline 0.3 & 0.0113849 & 0.0171511 & 0.0168645 & 0.0169404 \\
\hline 0.5 & 0.0093804 & 0.0150589 & 0.0157554 & 0.0157545 \\
\hline 0.7 & 0.0054698 & 0.0066738 & 0.0066753 & 0.0066903 \\
\hline 0.9 & 0.0008500 & 0.0005556 & 0.0008388 & 0.0009427 \\
\hline
\end{tabular}

The fluid velocities of $0,10,20,30,40$, and $50 \mathrm{~m} / \mathrm{s}$ are considered, and, with the increasing of the velocity, all of the five natural frequencies of the system decrease. To demonstrate the validity and accuracy of the proposed GITT approach, GITT solution for dimensionless free vibration frequencies for clamped-clamped pipes with $m_{f}=0$ and $k=0$ is calculated to compare with the results presented in the literature [42], where the excellent agreement between them can be found, as shown in Table 3.
4.3. Parametric Study. In this section, transverse displacement of axially FG pipes conveying fluid with clampedclamped boundary conditions is analyzed to illustrate the applicability of the proposed approach. Different values of the mass ratio $\beta$, Young's modulus ratio $E_{\text {ratio, the material }}$ distribution $k$, and the dimensionless flow velocity $v$ are chosen to assess their effects on the dynamic behavior of the system. In the following analysis, we use a relative high truncation order, $N W=16$, for a sufficient accuracy. 
TABLE 3: Influence of fluid velocity on the first five dimensionless natural frequencies of FG pipes conveying fluid $(k=1.0)$.

\begin{tabular}{|c|c|c|c|c|c|}
\hline $\begin{array}{l}\text { Fluid velocity } \\
(\mathrm{m} / \mathrm{s})\end{array}$ & $\omega_{1}$ & $\omega_{2}$ & $\omega_{3}$ & $\omega_{4}$ & $\omega_{5}$ \\
\hline 0 & $22.373^{*}$ & $61.673^{*}$ & $120.903^{*}$ & $199.859^{*}$ & $298.556^{*}$ \\
\hline 0 & $22.373^{* *}$ & $61.673^{* *}$ & $120.903^{* *}$ & $199.859^{* *}$ & $298.556^{* *}$ \\
\hline 0 & 26.866 & 74.323 & 145.936 & 241.576 & 361.572 \\
\hline 10 & 26.850 & 74.306 & 145.918 & 241.558 & 361.556 \\
\hline 20 & 26.801 & 74.255 & 145.865 & 241.506 & 361.508 \\
\hline 30 & 26.720 & 74.171 & 145.777 & 241.419 & 361.428 \\
\hline 40 & 26.605 & 74.052 & 145.653 & 241.296 & 361.315 \\
\hline 50 & 26.457 & 73.899 & 145.493 & 241.139 & 361.171 \\
\hline
\end{tabular}

*: dimensionless free vibration frequencies for clamped-clamped beams [42].

$* *$ : GITT solution for dimensionless free vibration frequencies for clamped-clamped pipes $\left(m_{f}=0\right.$ and $\left.k=0\right)$.

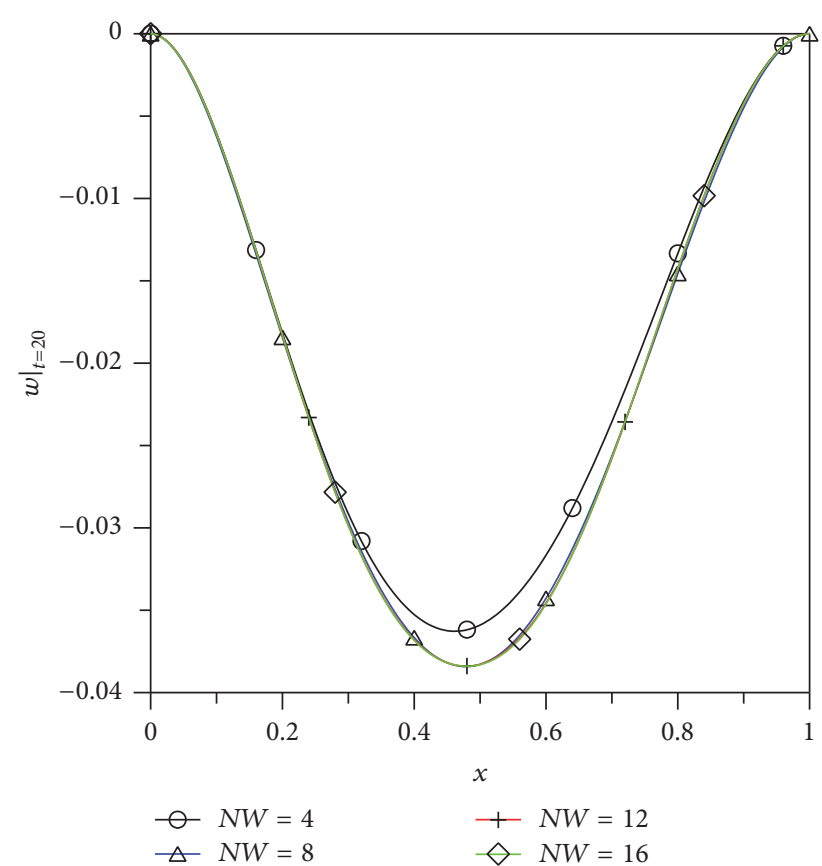

(a)

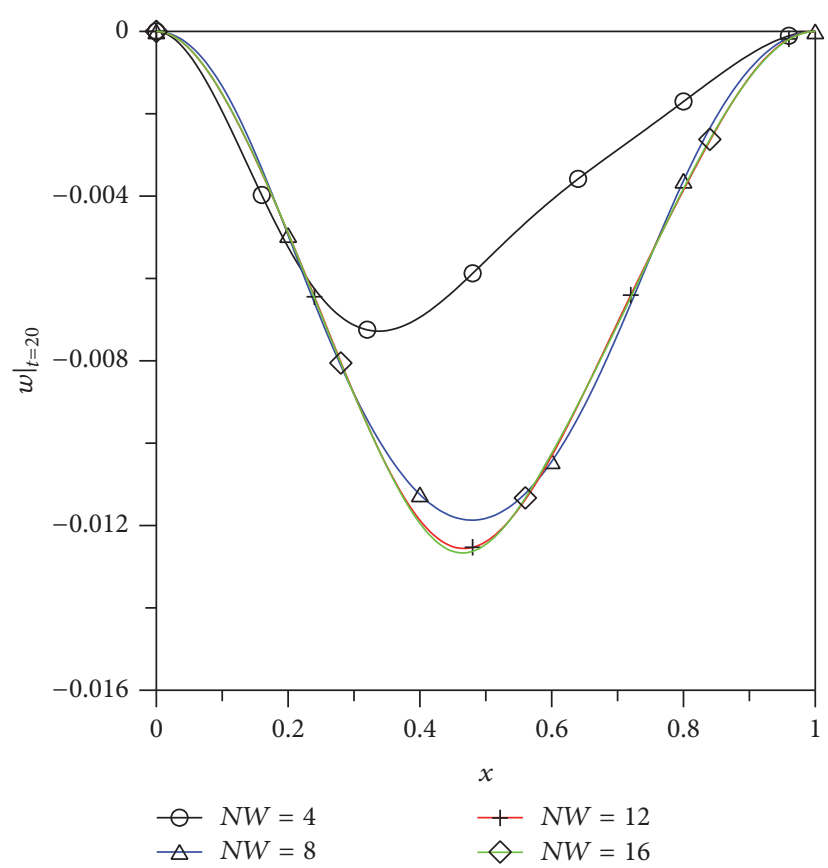

(b)

FIGURE 2: GITT solutions with different truncation orders $N W$ for the dimensionless transverse displacement profiles: (a) $\left.w(x, t)\right|_{t=20}$ for $v=1.0$ and (b) $\left.w(x, t)\right|_{t=20}$ for $v=3.0$ of FG pipes conveying fluid.

4.3.1. The Effect of Young's Modulus Variation. The first three dimensionless natural frequencies of the axially FG pipe conveying fluid for different Young's modulus ratios, powerlaw exponent, and mass ratios are tabulated in Tables 4-6, where the following parameters are adopted: $E_{l}=70 \mathrm{GPa}$, $E_{\text {ratio }}=E_{L} / E_{R}, \rho_{f}=1000 \mathrm{~kg} / \mathrm{m}^{3}, \rho_{\text {ratio }}=\rho_{L} / \rho_{R}=1.0$, and $\rho_{L} / \rho_{f}=4.0$. The mass ratio is calculated by $(2 \mathrm{a})-(2 \mathrm{~g})$ with the specified value of pipe thickness $t$ and $d=19.65 \mathrm{~mm}$. The flow velocity of the fluid is $20 \mathrm{~m} / \mathrm{s}$. For the specified modulus ratio and power exponent, all of the first three dimensionless natural frequencies increase with the decrease of the mass ratio. The effect of the modulus ratios on the fundamental frequency of fluid-conveying pipe with the mass ratio of 0.796 is presented in Figure 3. It is observed that the fundamental frequency decreases significantly with increasing of modulus ratio especially for large power exponent. On the other hand, no significant changes can be seen in the fundamental frequency for different modulus ratios for lower value of power exponent. Figure 4 illustrates the variation of the fundamental frequency with the power exponent for fluidconveying pipe with the mass ratio of 0.796 , which shows that the increase in power exponent causes the increase in frequency for $E_{\text {ratio }}<1$ and the decrease in frequency for $E_{\text {ratio }}>1$ and no changes occur for $E_{\text {ratio }}=1$.

4.3.2. The Effect of Material Distribution. To examine the effect of material distribution on the frequencies of the axially FG pipe conveying fluid, the integral transform solutions are obtained based on the material properties given in Section 4.1 and the fluid velocity of $20 \mathrm{~m} / \mathrm{s}$. The first 
TABLE 4: The variation of the first natural angular frequencies for different material distributions $k$ and mass ratios $\beta$ when flow velocity is $20 \mathrm{~m} / \mathrm{s}, E_{\text {ratio }}=E_{l} / E_{r}, \rho_{\text {ratio }}=\rho_{l} / \rho_{r}=1.0$, and $\rho_{l} / \rho_{f}=4.0$.

\begin{tabular}{|c|c|c|c|c|c|c|c|c|c|c|}
\hline$t(\mathrm{~mm})$ & $\beta$ & $E_{\text {ratio }}$ & $k=0.0$ & $k=0.1$ & $k=0.2$ & $k=0.5$ & $k=1.0$ & $k=2.0$ & $k=5.0$ & $k=10.0$ \\
\hline \multirow{5}{*}{1.0} & \multirow{5}{*}{0.796} & 0.25 & 22.1909 & 25.2702 & 27.1859 & 30.5936 & 33.4550 & 36.1690 & 39.0072 & 40.4687 \\
\hline & & 0.50 & 22.1909 & 23.3497 & 24.1498 & 25.6193 & 26.8588 & 28.0211 & 29.1967 & 29.7777 \\
\hline & & 1.00 & 22.1909 & 22.1909 & 22.1909 & 22.1909 & 22.1909 & 22.1909 & 22.1909 & 22.1909 \\
\hline & & 2.00 & 22.1909 & 21.5289 & 20.9829 & 19.8618 & 18.8849 & 17.9785 & 17.0936 & 16.6791 \\
\hline & & 4.00 & 22.1909 & 21.1690 & 20.2790 & 18.3220 & 16.5444 & 14.9059 & 13.3283 & 12.5955 \\
\hline \multirow{5}{*}{2.0} & \multirow{5}{*}{0.672} & 0.25 & 22.3008 & 25.3695 & 27.2788 & 30.6755 & 33.5282 & 36.2347 & 39.0667 & 40.5260 \\
\hline & & 0.50 & 22.3008 & 23.4554 & 24.2525 & 25.7159 & 26.9498 & 28.1068 & 29.2778 & 29.8571 \\
\hline & & 1.00 & 22.3008 & 22.3008 & 22.3008 & 22.3008 & 22.3008 & 22.3008 & 22.3008 & 22.3008 \\
\hline & & 2.00 & 22.3008 & 21.6413 & 21.0977 & 19.9830 & 19.0138 & 18.1167 & 17.2418 & 16.8313 \\
\hline & & 4.00 & 22.3008 & 21.2828 & 20.3968 & 18.4519 & 16.6913 & 15.0763 & 13.5273 & 12.8067 \\
\hline \multirow{5}{*}{3.0} & \multirow{5}{*}{0.587} & 0.25 & 22.3333 & 25.3989 & 27.3063 & 30.6998 & 33.5499 & 36.2543 & 39.0844 & 40.5430 \\
\hline & & 0.50 & 22.3333 & 23.4867 & 24.2829 & 25.7445 & 26.9767 & 28.1322 & 29.3018 & 29.8807 \\
\hline & & 1.00 & 22.3333 & 22.3333 & 22.3333 & 22.3333 & 22.3333 & 22.3333 & 22.3333 & 22.3333 \\
\hline & & 2.00 & 22.3333 & 21.6746 & 21.1317 & 20.0189 & 19.0520 & 18.1575 & 17.2856 & 16.8762 \\
\hline & & 4.00 & 22.3333 & 21.3165 & 20.4318 & 18.4904 & 16.7348 & 15.1266 & 13.5858 & 12.8688 \\
\hline
\end{tabular}

TABLE 5: The variation of the second natural angular frequencies for different material distributions $k$ and mass ratios $\beta$ when flow velocity is $20 \mathrm{~m} / \mathrm{s}, E_{\text {ratio }}=E_{l} / E_{r}, \rho_{\text {ratio }}=\rho_{l} / \rho_{r}=1.0$, and $\rho_{l} / \rho_{f}=4.0$.

\begin{tabular}{|c|c|c|c|c|c|c|c|c|c|c|}
\hline$t(\mathrm{~mm})$ & $\beta$ & $E_{\text {ratio }}$ & $k=0.0$ & $k=0.1$ & $k=0.2$ & $k=0.5$ & $k=1.0$ & $k=2.0$ & $k=5.0$ & $k=10.0$ \\
\hline \multirow{5}{*}{1.0} & \multirow{5}{*}{0.796} & 0.25 & 61.5004 & 69.4713 & 74.6411 & 84.2515 & 92.8974 & 101.469 & 110.495 & 114.810 \\
\hline & & 0.50 & 61.5004 & 64.4750 & 66.6003 & 70.6875 & 74.4028 & 78.0533 & 81.7840 & 83.5138 \\
\hline & & 1.00 & 61.5004 & 61.5004 & 61.5004 & 61.5004 & 61.5004 & 61.5004 & 61.5004 & 61.5004 \\
\hline & & 2.00 & 61.5004 & 59.8213 & 58.4126 & 55.3901 & 52.5094 & 49.6838 & 46.9156 & 45.7453 \\
\hline & & 4.00 & 61.5004 & 58.9166 & 56.6441 & 51.4604 & 46.2746 & 41.1824 & 36.2901 & 34.2703 \\
\hline \multirow{5}{*}{2.0} & \multirow{5}{*}{0.672} & 0.25 & 61.5959 & 69.5577 & 74.7221 & 84.3233 & 92.9617 & 101.527 & 110.547 & 114.860 \\
\hline & & 0.50 & 61.5959 & 64.5668 & 66.6895 & 70.7715 & 74.4821 & 78.1281 & 81.8547 & 83.5830 \\
\hline & & 1.00 & 61.5959 & 61.5959 & 61.5959 & 61.5959 & 61.5959 & 61.5959 & 61.5959 & 61.5959 \\
\hline & & 2.00 & 61.5959 & 59.9190 & 58.5124 & 55.4955 & 52.6216 & 49.8040 & 47.0441 & 45.8770 \\
\hline & & 4.00 & 61.5959 & 59.0156 & 56.7467 & 51.5737 & 46.4032 & 41.3315 & 36.4620 & 34.4515 \\
\hline \multirow{5}{*}{3.0} & \multirow{5}{*}{0.587} & 0.25 & 61.6276 & 69.5864 & 74.7490 & 84.3471 & 92.9830 & 101.546 & 110.564 & 114.876 \\
\hline & & 0.50 & 61.6276 & 64.5973 & 66.7191 & 70.7995 & 74.5085 & 78.1529 & 81.8782 & 83.6060 \\
\hline & & 1.00 & 61.6276 & 61.6276 & 61.6276 & 61.6276 & 61.6276 & 61.6276 & 61.6276 & 61.6276 \\
\hline & & 2.00 & 61.6276 & 59.9515 & 58.5456 & 55.5305 & 52.6589 & 49.8439 & 47.0868 & 45.9207 \\
\hline & & 4.00 & 61.6276 & 59.0485 & 56.7809 & 51.6114 & 46.4459 & 41.3809 & 36.5192 & 34.5117 \\
\hline
\end{tabular}

five natural angular frequencies for different mass ratios and power exponents are reported in Table 7. All of the natural frequencies $\left(\omega_{1}, \omega_{2}, \ldots, \omega_{5}\right)$ increase with the power exponent for the specified mass ratio. Note that the natural frequencies increase with the decrease of the mass ratio for the case of $k=0.0$, which means the pipe is made of singlecomponent, aluminum. However, when considering the FG material with the power exponents $k=0.1,0.2, \ldots, 10$, the natural frequencies decrease with the decrease of the mass ratio.

The variation of vibration amplitudes for different material distributions and mass ratios is listed in Table 8 . It can be seen that the vibration amplitude decreases with the increase of the power exponent and increases with the decrease of the mass ratio.

In addition, the effect of material distribution on the critical velocity of fluid-conveying pipe with the material properties given in Section 4.1 is analyzed, as shown in Figure 5, which exhibits the variation of the fundamental frequency with the flow velocity of fluid for different power exponents. It can be clearly seen that the fundamental frequency decreases with the flow velocity for the specified power exponent, and the critical velocity $\left(\omega_{1}=0\right)$ increases with the power exponent. 
TABLE 6: The variation of the third natural angular frequencies for different material distributions $k$ and mass ratios $\beta$ when flow velocity is $20 \mathrm{~m} / \mathrm{s}, E_{\text {ratio }}=E_{l} / E_{r}, \rho_{\text {ratio }}=\rho_{l} / \rho_{r}=1.0$, and $\rho_{l} / \rho_{f}=4.0$.

\begin{tabular}{|c|c|c|c|c|c|c|c|c|c|c|}
\hline$t(\mathrm{~mm})$ & $\beta$ & $E_{\text {ratio }}$ & $k=0.0$ & $k=0.1$ & $k=0.2$ & $k=0.5$ & $k=1.0$ & $k=2.0$ & $k=5.0$ & $k=10.0$ \\
\hline \multirow{5}{*}{1.0} & \multirow{5}{*}{0.796} & 0.25 & 120.726 & 135.934 & 145.948 & 164.997 & 182.693 & 200.618 & 219.333 & 227.933 \\
\hline & & 0.50 & 120.726 & 126.374 & 130.466 & 138.522 & 146.073 & 153.635 & 161.360 & 164.876 \\
\hline & & 1.00 & 120.726 & 120.726 & 120.726 & 120.726 & 120.726 & 120.726 & 120.726 & 120.726 \\
\hline & & 2.00 & 120.726 & 117.564 & 114.895 & 109.017 & 103.185 & 97.3618 & 91.6997 & 89.3743 \\
\hline & & 4.00 & 120.726 & 115.872 & 111.598 & 101.632 & 91.1682 & 80.6355 & 70.6481 & 66.6398 \\
\hline \multirow{5}{*}{2.0} & \multirow{5}{*}{0.672} & 0.25 & 120.822 & 136.020 & 146.028 & 165.068 & 182.757 & 200.677 & 219.386 & 227.984 \\
\hline & & 0.50 & 120.822 & 126.466 & 130.555 & 138.606 & 146.153 & 153.711 & 161.432 & 164.946 \\
\hline & & 1.00 & 120.822 & 120.822 & 120.822 & 120.822 & 120.822 & 120.822 & 120.822 & 120.822 \\
\hline & & 2.00 & 120.822 & 117.663 & 114.996 & 109.124 & 103.298 & 97.4820 & 91.8275 & 89.5047 \\
\hline & & 4.00 & 120.822 & 115.972 & 111.702 & 101.747 & 91.2969 & 80.7826 & 70.8185 & 66.8177 \\
\hline \multirow{5}{*}{3.0} & \multirow{5}{*}{0.587} & 0.25 & 120.855 & 136.049 & 146.056 & 165.092 & 182.779 & 200.697 & 219.405 & 228.002 \\
\hline & & 0.50 & 120.855 & 126.498 & 130.586 & 138.635 & 146.180 & 153.737 & 161.457 & 164.970 \\
\hline & & 1.00 & 120.855 & 120.855 & 120.855 & 120.855 & 120.855 & 120.855 & 120.855 & 120.855 \\
\hline & & 2.00 & 120.855 & 117.697 & 115.031 & 109.160 & 103.336 & 97.5231 & 91.8713 & 89.5494 \\
\hline & & 4.00 & 120.855 & 116.006 & 111.738 & 101.786 & 91.3409 & 80.8330 & 70.8770 & 66.8789 \\
\hline
\end{tabular}

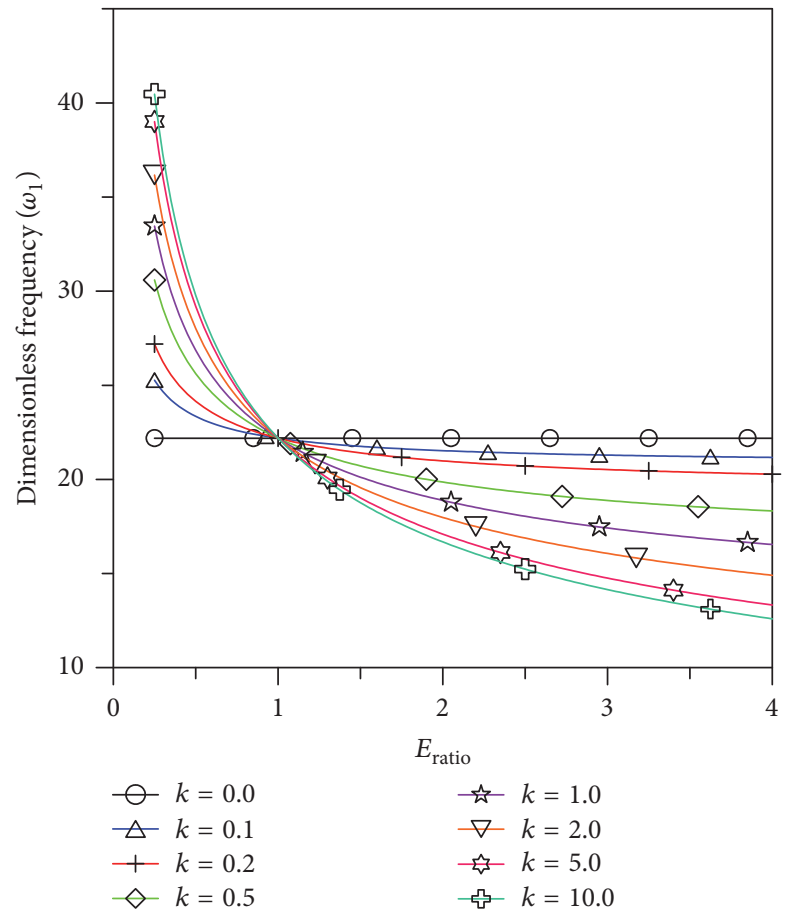

Figure 3: Variation of the dimensionless frequency $\left(\omega_{1}\right)$ with Young's modulus ratio.

\section{Conclusions}

The generalized integral transform technique (GITT) has proved in this paper to be a good approach for the analysis of dynamic behavior of an axially FG pipe conveying fluid, providing an accurate numerical-analytical solution for the natural frequencies and transverse displacements. The investigation shows that the solutions converge to the values

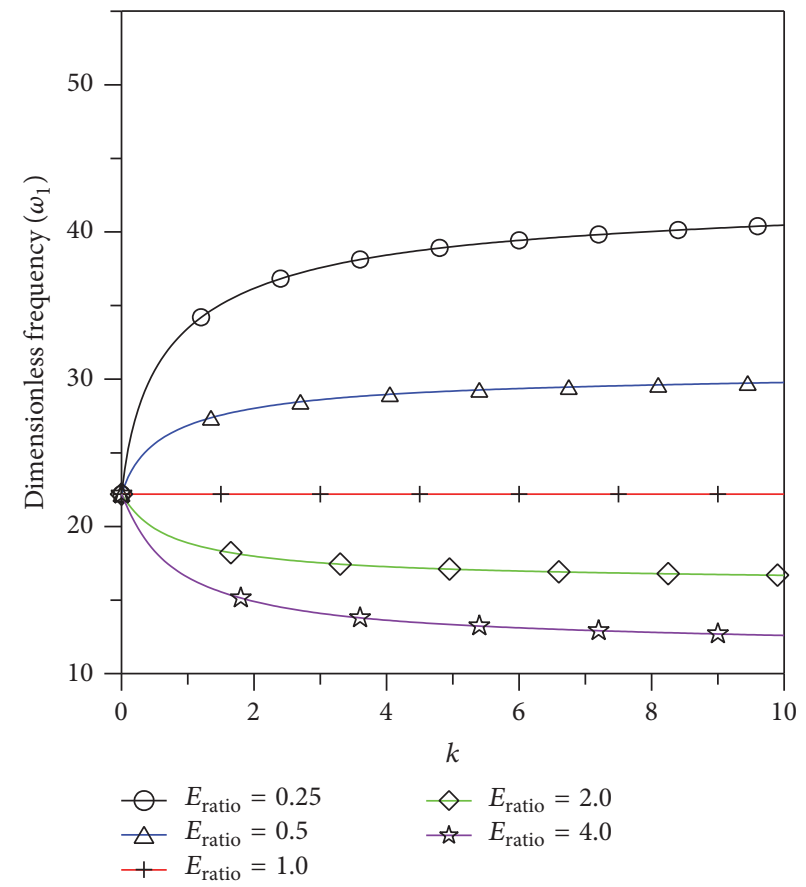

FIGURE 4: Variation of the dimensionless frequency $\left(\omega_{1}\right)$ with power exponent $(k)$.

with three significant figures at a reasonable low truncation order $N \leq 12$ for $v=1.0$, and the increasing of $v$ can make the solution with a relatively slow convergence. The numerical results obtained are in good agreement with the ones presented in the literature. The parametric studies indicate that the fundamental frequency decreases significantly with increasing of modulus ratio especially for large power exponent, while no significant changes can be seen 
TABLE 7: The variation of natural angular frequencies for different material distributions $k$ and mass ratios $\beta$ when flow velocity is $20 \mathrm{~m} / \mathrm{s}$.

\begin{tabular}{|c|c|c|c|c|c|c|c|c|c|c|}
\hline$t(\mathrm{~mm})$ & $\beta$ & $\omega_{i}$ & $k=0.0$ & $k=0.1$ & $k=0.2$ & $k=0.5$ & $k=1.0$ & $k=2.0$ & $k=5.0$ & $k=10.0$ \\
\hline \multirow{5}{*}{1.0} & \multirow{5}{*}{0.796} & $i=1$ & 22.1835 & 23.8868 & 24.9026 & 26.4715 & 27.4513 & 28.1186 & 28.8294 & 29.4111 \\
\hline & & $i=2$ & 61.5036 & 65.7479 & 68.3906 & 72.7928 & 76.1318 & 79.0050 & 81.8223 & 83.2525 \\
\hline & & $i=3$ & 120.732 & 128.668 & 133.700 & 142.428 & 149.573 & 156.161 & 162.514 & 165.285 \\
\hline & & $i=4$ & 199.693 & 212.486 & 220.721 & 235.305 & 247.679 & 259.404 & 270.748 & 275.362 \\
\hline & & $i=5$ & 298.392 & 317.258 & 329.420 & 351.361 & 370.905 & 389.776 & 407.194 & 413.686 \\
\hline \multirow{5}{*}{2.0} & \multirow{5}{*}{0.672} & $i=1$ & 22.2976 & 23.8315 & 24.6962 & 25.9020 & 26.4864 & 26.7497 & 27.1061 & 27.5738 \\
\hline & & $i=2$ & 61.5972 & 65.3592 & 67.5855 & 71.0306 & 73.3695 & 75.2171 & 77.0180 & 78.0331 \\
\hline & & $i=3$ & 120.825 & 127.785 & 131.993 & 138.872 & 144.125 & 148.770 & 153.121 & 155.007 \\
\hline & & $i=4$ & 199.781 & 210.932 & 217.798 & 229.340 & 238.617 & 247.159 & 255.195 & 258.328 \\
\hline & & $i=5$ & 298.477 & 314.839 & 324.951 & 342.322 & 357.127 & 371.143 & 383.736 & 388.144 \\
\hline \multirow{5}{*}{3.0} & \multirow{5}{*}{0.587} & $i=1$ & 22.3317 & 23.7692 & 24.5496 & 25.5605 & 25.9443 & 26.0152 & 26.2112 & 26.6270 \\
\hline & & $i=2$ & 61.6283 & 65.1117 & 67.1047 & 70.0359 & 71.8650 & 73.2123 & 74.5377 & 75.3643 \\
\hline & & $i=3$ & 120.856 & 127.252 & 131.000 & 136.890 & 141.179 & 144.870 & 148.272 & 149.752 \\
\hline & & $i=4$ & 199.812 & 210.013 & 216.115 & 226.033 & 233.735 & 240.712 & 247.171 & 249.620 \\
\hline & & $i=5$ & 298.508 & 313.428 & 322.400 & 337.340 & 349.740 & 361.370 & 371.651 & 375.089 \\
\hline
\end{tabular}

TABLE 8: The variation of vibration amplitudes for different material distributions $k$ and mass ratios $\beta$ when flow velocity is $20 \mathrm{~m} / \mathrm{s}$.

\begin{tabular}{lccccccccc}
\hline$t(\mathrm{~mm})$ & $\beta$ & $k=0.0$ & $k=0.1$ & $k=0.2$ & $k=0.5$ & $k=1.0$ & $k=2.0$ & $k=5.0$ & $k=10.0$ \\
\hline 1.0 & 0.796 & 0.05064 & 0.04742 & 0.04562 & 0.04265 & 0.04067 & 0.03966 & 0.03864 & 0.03787 \\
2.0 & 0.672 & 0.05071 & 0.04779 & 0.04607 & 0.04365 & 0.04226 & 0.04176 & 0.04093 & 0.04042 \\
3.0 & 0.587 & 0.05076 & 0.04794 & 0.04657 & 0.04431 & 0.04315 & 0.04276 & 0.04237 & 0.04192 \\
\hline
\end{tabular}

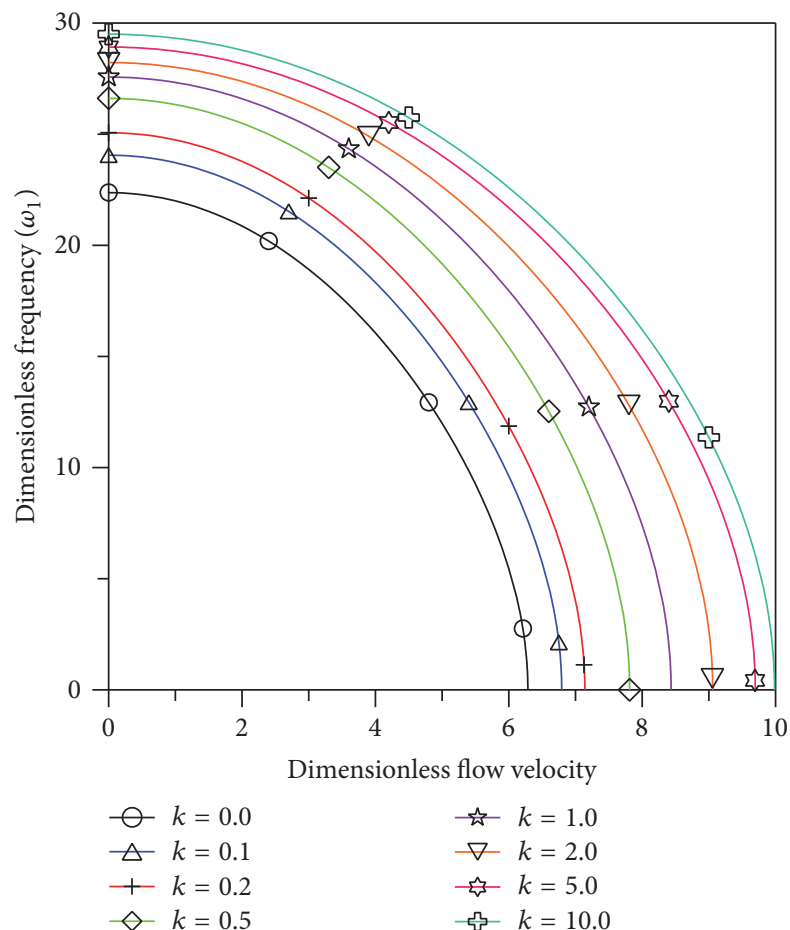

FIGURE 5: Variation of the dimensionless frequency $\left(\omega_{1}\right)$ with dimensionless flow velocity $(v)$.

in the fundamental frequency for different modulus ratios for lower value of power exponent. The increase in power exponent causes the increase in frequency for $E_{\text {ratio }}<1$ and the decrease in frequency for $E_{\text {ratio }}>1$ and no changes occur for $E_{\text {ratio }}=1$. The natural frequency increases with the power exponent, and the natural frequency decreases with the decrease of the mass ratio when considering the pipe is made of the FG material with the power exponents $k=0.1,0.2, \ldots, 10$. The vibration amplitude decreases with the increase of the power exponent and increases with the decrease of the mass ratio. The critical velocity of fluidconveying pipe increases with the power exponent. For future investigation, the proposed approach can be employed to predict the dynamic behavior of a transversally FG pipe conveying fluid and for more general boundary conditions.

\section{Competing Interests}

The authors declare that they have no competing interests.

\section{Acknowledgments}

The work was supported by National Natural Science Foundation of China (Grant no. 51509258), Science Foundation of China University of Petroleum, Beijing (Grants nos. 2462013YJRC003 and C201602), National Key Research and Development Plan (Grant no. 2016YFC0303700), and CNPq (Grant no. 306618/2010-9) and CAPES and FAPERJ (Grant no. E-26/102.871/2012) of Brazil.

\section{References}

[1] M. H. Sadeghi and M. H. Karimi-Dona, "Dynamic behavior of a fluid conveying pipe subjected to a moving sprung massan FEM-state space approach," International Journal of Pressure Vessels and Piping, vol. 88, no. 4, pp. 123-131, 2011. 
[2] M. P. Païdoussis and G. X. Li, "Pipes conveying fluid: a model dynamical problem," Journal of Fluids and Structures, vol. 7, no. 2, pp. 137-204, 1993.

[3] M. P. Païdoussis, Fluid-Structure Interactions: Slender Structures and Axial Flow, Academic Press, San Diego, Calif, USA, 1998.

[4] M. P. Païdoussis, "The canonical problem of the fluid-conveying pipe and radiation of the knowledge gained to other dynamics problems across Applied Mechanics," Journal of Sound and Vibration, vol. 310, no. 3, pp. 462-492, 2008.

[5] R. H. Long, "Experimental and theoretical study of transverse vibration of a tube containing flowing fluid," Journal of Applied Mechanics Transactions of the ASME, vol. 22, no. 1, pp. 65-68, 1955.

[6] M. P. Païdoussis and N. T. Issid, "Dynamic stability of pipes conveying fluid," Journal of Sound and Vibration, vol. 33, no. 3 , pp. 267-294, 1974.

[7] M. P. Païdoussis, "Flutter of conservative systems of pipes conveying in compressible fluid," Journal of Mechanical Engineering Science, vol. 17, no. 1, pp. 19-25, 1975.

[8] M.-R. Xu, S.-P. Xu, and H.-Y. Guo, "Determination of natural frequencies of fluid-conveying pipes using homotopy perturbation method," Computers \& Mathematics with Applications, vol. 60 , no. 3, pp. 520-527, 2010.

[9] L. Liu and F. Xuan, "Flow-induced vibration analysis of supported pipes conveying pulsating fluid using precise integration method," Mathematical Problems in Engineering, vol. 2010, Article ID 806475, 15 pages, 2010.

[10] J. H. Ginsberg, "The dynamic stability of a pipe conveying a pulsatile flow," International Journal of Engineering Science, vol. 11, no. 9, pp. 1013-1024, 1973.

[11] J. D. Jin and Z. Y. Song, "Parametric resonances of supported pipes conveying pulsating fluid," Journal of Fluids and Structures, vol. 20, no. 6, pp. 763-783, 2005.

[12] L. N. Panda and R. C. Kar, "Nonlinear dynamics of a pipe conveying pulsating fluid with combination, principal parametric and internal resonances," Journal of Sound and Vibration, vol. 309, no. 3-5, pp. 375-406, 2008.

[13] F.-Q. Zhao, Z.-M. Wang, Z.-Y. Feng, and H.-Z. Liu, "Stability analysis of Maxwell viscoelastic pipes conveying fluid with both ends simply supported," Applied Mathematics and Mechanics, vol. 22, no. 12, pp. 1436-1445, 2001.

[14] Y. L. Zhang, D. G. Gorman, and J. M. Reese, "A modal and damping analysis of viscoelastic Timoshenko tubes conveying fluid," International Journal for Numerical Methods in Engineering, vol. 50, no. 2, pp. 419-433, 2001.

[15] Z.-M. Wang, Z.-W. Zhang, and F.-Q. Zhao, "Stability analysis of viscoelastic curved pipes conveying fluid," Applied Mathematics and Mechanics, vol. 26, no. 6, pp. 807-813, 2005.

[16] X. Yang, T. Yang, and J. Jin, "Dynamic stability of a beam-model viscoelastic pipe for conveying pulsative fluid," Acta Mechanica Solida Sinica, vol. 20, no. 4, pp. 350-356, 2007.

[17] V. I. Gulyayev and E. Y. Tolbatov, "Forced and self-excited vibrations of pipes containing mobile boiling fluid clots," Journal of Sound and Vibration, vol. 257, no. 3, pp. 425-437, 2002.

[18] Y. S. Seo, W. B. Jeong, S. H. Jeong, J. S. Oh, and W. S. Yoo, "Finite element analysis of forced vibration for a pipe conveying harmonically pulsating fluid," JSME International Journal, Series C: Mechanical Systems, Machine Elements and Manufacturing, vol. 48, no. 4, pp. 688-694, 2006.

[19] F. Liang and B. C. Wen, "Forced vibrations with internal resonance of a pipe conveying fluid under external periodic excitation," Acta Mechanica Solida Sinica, vol. 24, no. 6, pp. 477483, 2011.

[20] H.-B. Zhai, Z.-Y. Wu, Y.-S. Liu, and Z.-F. Yue, "Dynamic response of pipeline conveying fluid to random excitation," Nuclear Engineering and Design, vol. 241, no. 8, pp. 2744-2749, 2011.

[21] H.-B. Zhai, Z.-Y. Wu, Y.-S. Liu, and Z.-F. Yue, "In-plane dynamic response analysis of curved pipe conveying fluid subjected to random excitation," Nuclear Engineering and Design, vol. 256, pp. 214-226, 2013.

[22] R. Kadoli and N. Ganesan, "Parametric resonance of a composite cylindrical shell containing pulsatile flow of hot fluid," Composite Structures, vol. 65, no. 3-4, pp. 391-404, 2004.

[23] N. Ganesan and R. Kadoli, "A study on the dynamic stability of a cylindrical shell conveying a pulsatile flow of hot fluid," Journal of Sound and Vibration, vol. 274, no. 3-5, pp. 953-984, 2004.

[24] G. G. Sheng and X. Wang, "Thermomechanical vibration analysis of a functionally graded shell with flowing fluid," European Journal of Mechanics-A/Solids, vol. 27, no. 6, pp. 1075-1087, 2008.

[25] Q. Qian, L. Wang, and Q. Ni, "Instability of simply supported pipes conveying fluid under thermal loads," Mechanics Research Communications, vol. 36, no. 3, pp. 413-417, 2009.

[26] M. Hosseini and S. A. Fazelzadeh, "Thermomechanical stability analysis of functionally graded thin-walled cantilever pipe with flowing fluid subjected to axial load," International Journal of Structural Stability and Dynamics, vol. 11, no. 3, pp. 513-534, 2011.

[27] H.-S. Shen, Functionally Graded Materials : Nonlinear Analysis of Plates and Shells, CRC Press, Boca Raton, Fla, USA, 2009.

[28] Z. Zhong, L. Wu, and W. Chen, Mechanics of Functionally Graded Materials and Structures, Nova Science, New York, NY, USA, 2012.

[29] Y. Huang and X.-F. Li, "A new approach for free vibration of axially functionally graded beams with non-uniform crosssection," Journal of Sound and Vibration, vol. 329, no. 11, pp. 2291-2303, 2010.

[30] Y. Huang, L.-E. Yang, and Q.-Z. Luo, "Free vibration of axially functionally graded Timoshenko beams with non-uniform cross-section," Composites Part B: Engineering, vol. 45, no. 1, pp. 1493-1498, 2013.

[31] A. Shahba, R. Attarnejad, M. T. Marvi, and S. Hajilar, "Free vibration and stability analysis of axially functionally graded tapered Timoshenko beams with classical and non-classical boundary conditions," Composites Part B: Engineering, vol. 42, no. 4, pp. 801-808, 2011.

[32] A. Shahba and S. Rajasekaran, "Free vibration and stability of tapered Euler-Bernoulli beams made of axially functionally graded materials," Applied Mathematical Modelling, vol. 36, no. 7, pp. 3094-3111, 2012.

[33] M. Şimşek, T. Kocatürk, and Ş. D. Akbaş, "Dynamic behavior of an axially functionally graded beam under action of a moving harmonic load," Composite Structures, vol. 94, no. 8, pp. 23582364, 2012.

[34] A. E. Alshorbagy, M. A. Eltaher, and F. F. Mahmoud, "Free vibration characteristics of a functionally graded beam by finite element method," Applied Mathematical Modelling, vol. 35, no. 1, pp. 412-425, 2011.

[35] C. An and J. Su, "Dynamic response of clamped axially moving beams: integral transform solution," Applied Mathematics and Computation, vol. 218, no. 2, pp. 249-259, 2011. 
[36] C. An and J. Su, "Dynamic analysis of axially moving orthotropic plates: integral transform solution," Applied Mathematics and Computation, vol. 228, pp. 489-507, 2014.

[37] J. Gu, C. An, M. Duan, C. Levi, and J. Su, "Integral transform solutions of dynamic response of a clamped-clamped pipe conveying fluid," Nuclear Engineering and Design, vol. 254, pp. 237-245, 2015.

[38] C. An and J. Su, "Dynamic behavior of pipes conveying gasliquid two-phase flow," Nuclear Engineering and Design, vol. 292, pp. 204-212, 2015.

[39] C. F. T. Matt, "On the application of generalized integral transform technique to wind-induced vibrations on overhead conductors," International Journal for Numerical Methods in Engineering, vol. 78, no. 8, pp. 901-930, 2009.

[40] J.-J. Gu, C. An, C. Levi, and J. Su, "Prediction of vortex-induced vibration of long flexible cylinders modeled by a coupled nonlinear oscillator: integral transform solution," Journal of Hydrodynamics, vol. 24, no. 6, pp. 888-898, 2012.

[41] C. F. Matt, "Simulation of the transverse vibrations of a cantilever beam with an eccentric tip mass in the axial direction using integral transforms," Applied Mathematical Modelling, vol. 37, no. 22, pp. 9338-9354, 2013.

[42] A. W. Leissa and M. S. Qatu, Vibrations of Continuous Systems, McGrawHill, New York, NY, USA, 2011.

[43] S. Wolfram, The Mathematica Book, Wolfram Media/Cambridge University Press, Champaign, IIl, USA, 5th edition, 2003. 


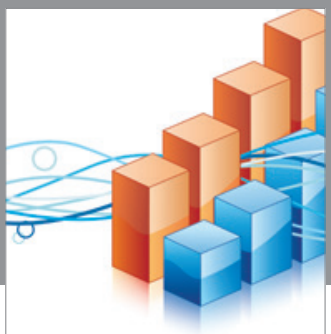

Advances in

Operations Research

vatem alat4

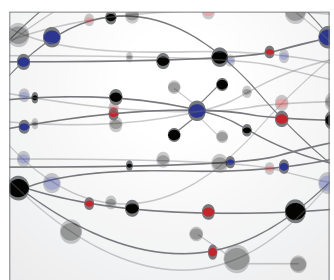

\section{The Scientific} World Journal
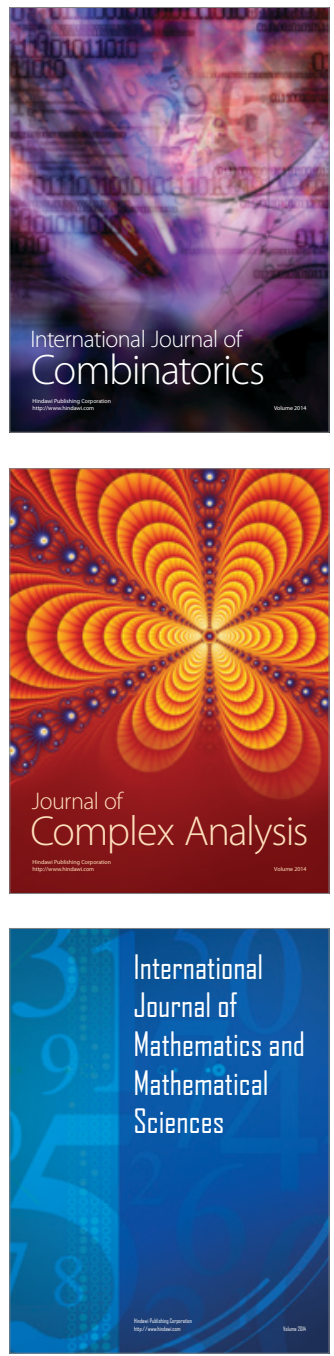
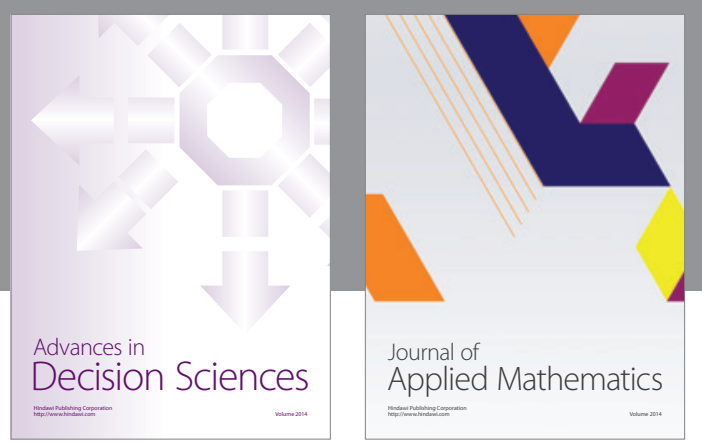

Algebra

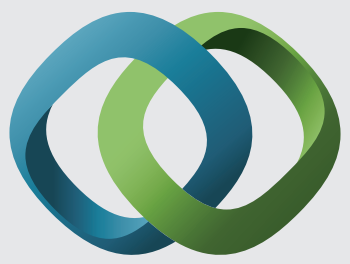

\section{Hindawi}

Submit your manuscripts at

https://www.hindawi.com
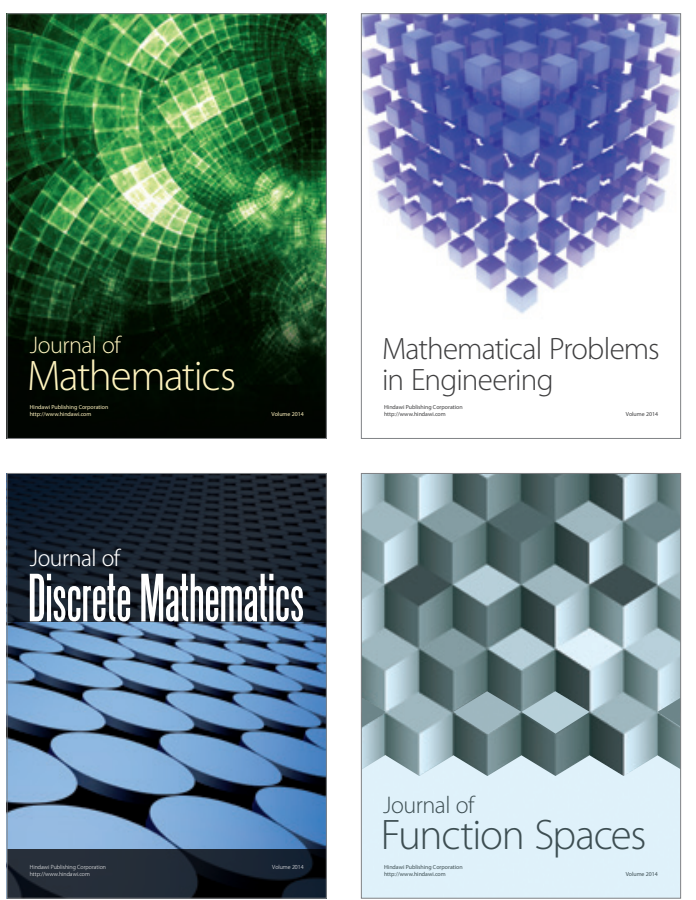

Mathematical Problems in Engineering
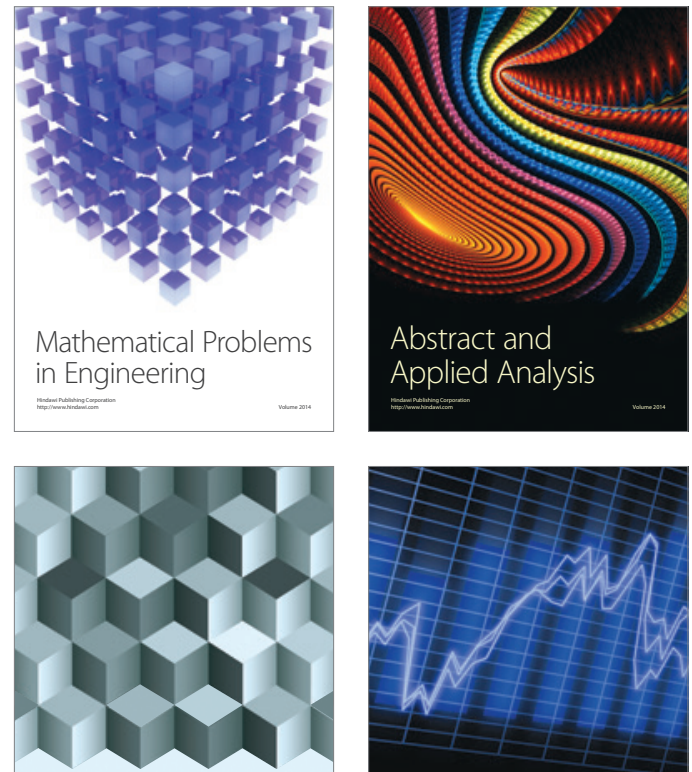

Journal of

Function Spaces

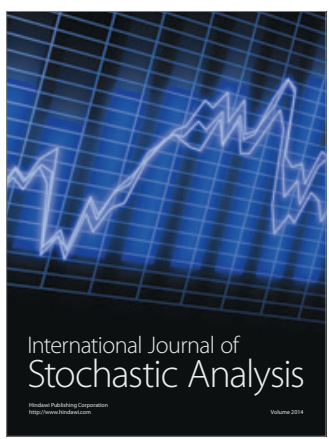

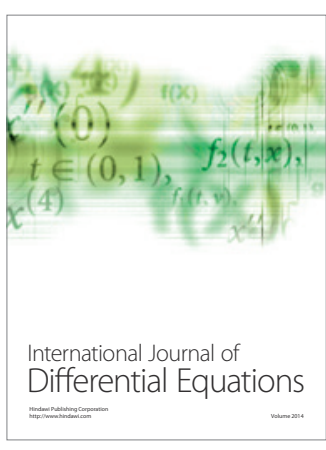
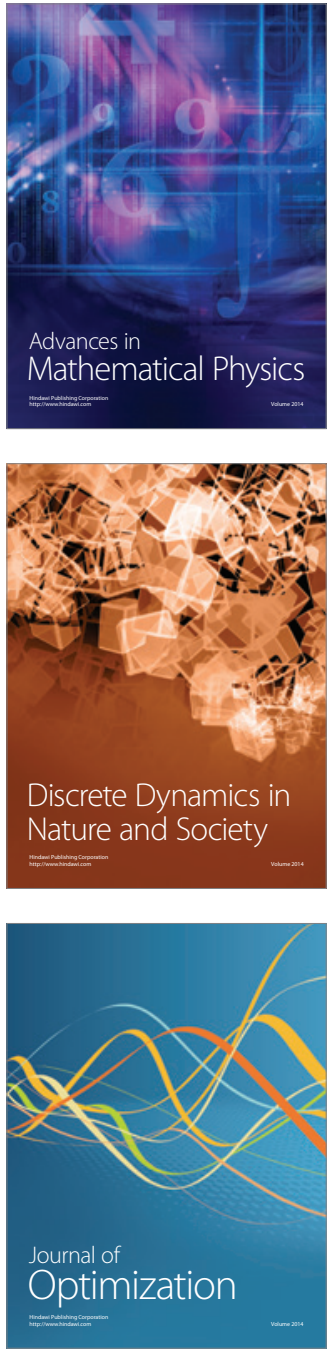